\title{
LDL-cholesterol and body mass index among Japanese schoolchildren: a population-based cross-sectional study
}

Takako Shirasawa ${ }^{{ }^{*},}$, Hirotaka Ochiai ${ }^{1}$, Tadahiro Ohtsu ${ }^{1}$, Rimei Nishimura ${ }^{2}$, Aya Morimoto $^{2}$, Hiromi Hoshino ${ }^{1}$, Naoko Tajima ${ }^{3}$ and Akatsuki Kokaze ${ }^{1}$

\begin{abstract}
Background: Serum low-density lipoprotein cholesterol (LDL-C) is one of the most important risk factors for coronary heart disease. The aim of the present study was to investigate the relationship between LDL-C and body mass index (BMI) in population-based Japanese schoolchildren.

Methods: The subjects comprised all fourth graders and seventh graders in Ina Town, Saitama Prefecture, Japan, during 2002-2009. Information about each subject's age, sex, and family history of hypercholesterolemia was collected using a self-administered questionnaire. The body height, weight, and LDL-C were measured for each child. LDL-C was measured using the direct method. According to the LDL-C criteria of the Japan Atherosclerosis Society, LDL-C level was categorized into three subgroups: acceptable, $<110 \mathrm{mg} / \mathrm{dL}$; borderline, 110-139 mg/dL; and high, $\geq 140 \mathrm{mg} / \mathrm{dL}$. Children with either borderline or high LDL-C level were considered to have high-normal LDL-C (HLDL-C).

Results: Data from a total of 5869 subjects were analyzed. A higher BMl category was associated with a higher prevalence of HLDL-C regardless of sex or grade level $(P<0.05)$. When compared with the $<50$ th percentile BMl category, the odds ratio (OR) for HLDL-C was statistically significant in the 75th to 84th percentile category of fourth-grade boys (OR: 1.95, 95\% confidence interval (95\% Cl): 1.28-2.97), the 85th to 94th percentile of fourth-grade girls $(2.52,1.74-3.64)$, and the 85th to 94th percentile of seventh-grade boys $(2.04,1.31-3.20)$ and girls $(1.90,1.24-2.91)$.
\end{abstract}

Conclusion: A statistically significant association between LDL-C levels and BMI was observed in Japanese school children.

Keywords: Serum low-density lipoprotein, Body mass index, Schoolchildren

\section{Background}

Some studies have reported that serum cholesterol levels have increased among Japanese children [1,2]. Previous studies have reported that childhood serum lipid levels and body mass index (BMI) are strongly correlated with those levels in middle age [3,4]. Moreover, a higher BMI during childhood is associated with increased risk of coronary heart disease (CHD) [5]. Therefore, it is very important to prevent childhood obesity, which may help prevent atherosclerosis and CHD in the future.

\footnotetext{
* Correspondence: shirasawa@med.showa-u.ac.jp

${ }^{1}$ Department of Public Health, Showa University School of Medicine, 1-5-8 Hatanodai, Shinagawa-ku, Tokyo 142-8555, Japan

Full list of author information is available at the end of the article
}

Serum low-density lipoprotein cholesterol (LDL-C) has been reported to be one of the most important risk factors of CHD [6,7]. Some studies have reported that an association of BMI with total cholesterol (TC) or highdensity lipoprotein cholesterol (HDL-C) among children $[1,2,8]$. However, LDL-C levels have not been measured often among Japanese children at the population level $[9,10]$.

The determination of serum LDL-C level is generally done using the Friedewald calculation, for which fasting serum triglyceride (TG) level is needed [11]. However, it is often difficult to obtain a fasting lipid profile in large population surveys $[12,13]$. Thus, some assays for the direct determination of serum LDL-C level that can be

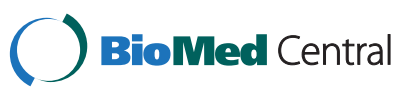


used with non-fasting serum samples have been developed [14]. Since this method is applicable to non-fasting serum samples $[15,16]$, it is useful for the evaluation of dyslipidemia in healthy schoolchildren.

Accordingly, the aim of the present study was to investigate the relationship between LDL-C measured using the direct method and BMI in population-based Japanese schoolchildren.

\section{Methods}

\section{Subjects and setting}

As a part of its community health services, the town of Ina in Saitama Prefecture, Japan, has provided annual childhood health check-ups to help prevent lifestylerelated diseases since 1994; studies of this program have been reported [17-22]. The present study was conducted as a part of the program.

The subjects of this study comprised all fourth graders (age 9-10 years) and all seventh graders (age 12-13 years) who lived in Ina between 2002 and 2009. Written informed consent was obtained from each child's parent or guardian. The study protocol was approved by the Medical Ethics Committee of Showa University School of Medicine.

\section{Variables and their measurement}

The following information was collected using a selfadministered questionnaire completed by each child: sex, age, and exercise other than physical education (daily, sometimes, or none). Additionally, each subject's parent or guardian was asked to complete a selfadministered questionnaire about parental history of hypercholesterolemia (Yes or No).

Measurements of height and weight were performed annually during 2002-2009. The same examination protocol was used annually to ensure uniformity of quality and precision of assessment. For the measurements, all participants were asked to remove their shoes and socks, after which their height and weight were measured in increments of $0.1 \mathrm{~cm}$ and $0.1 \mathrm{~kg}$, respectively, while they were wearing light clothing. BMI was calculated as body weight $(\mathrm{kg})$ divided by the square of the height $\left(\mathrm{m}^{2}\right)$.

Venous blood samples were drawn from the study subjects to measure serum levels of LDL-C. LDL-C was measured by routine automated laboratory methods. The levels of LDL-C were determined using the CholesterolLDL Kit (Daiichi Pure Chemicals, Japan) [17]. According to the LDL-C criteria of the Japan Atherosclerosis Society [9], the LDL-C level was categorized into three subgroups: acceptable, < $110 \mathrm{mg} / \mathrm{dL}$; borderline, 110-139 mg/dL; or high, $\geq 140 \mathrm{mg} / \mathrm{dL}$. Children with either borderline or high LDL-C level were considered to have high-normal LDL-C (HLDL-C). BMI was classified into five categories
(< 50th, 50th to 74th, 75th to 84th, 85th to 94th, and $\geq$ 95th percentile) according to a previous study [18].

\section{Data analysis methods}

The Mann-Whitney $U$-test or chi-squared test was used to compare characteristics between boys and girls. The normality of distribution was tested for each variable. In the stratified analysis by sex and grade, the relationship between LDL-C and BMI was investigated using the chisquared test and a logistic regression model. A $P$ value of less than 0.05 was considered statistically significant and $0.05 \leq P<0.1$ was regarded as marginally significant. All data were analyzed using SPSS 16.0 J (IBM, Chicago, IL, USA).

\section{Results}

Among 5950 subjects, 81 were excluded from the analysis because of refusal to participate or school absence. Thus, data from a total of 5869 subjects were analyzed. The participation rate was $98.6 \%$.

Table 1 shows characteristics of the subjects. Of the 5869 children, 3168 were fourth graders (1645 boys and 1523 girls) and 2701 were seventh graders (1380 boys and 1321 girls), with median age of 9.0 and 12.0 years, respectively. Median BMIs were 16.6 and $16.3 \mathrm{~kg} / \mathrm{m}^{2}$ for fourth-grade boys and girls, respectively, and 18.1 and $18.3 \mathrm{~kg} / \mathrm{m}^{2}$ for seventh-grade boys and girls. The BMIs were significantly higher in boys than in girls regardless of grade (fourth grade, $P<0.001$; seventh grade, $P=0.036)$. Median LDL-C levels for fourth-grade boys and girls were 90.0 and $95.0 \mathrm{mg} / \mathrm{dL}$, respectively, whereas those for seventh-grade boys and girls were 86.0 and $93.0 \mathrm{mg} / \mathrm{dL}$. In both grades, LDL-C was significantly higher in girls than in boys $(P<0.001)$. The proportion of HLDL-C in fourth-grade boys and girls was $18.8 \%$ and $24.9 \%$, respectively, and for seventh-grade boys and girls $15.6 \%$ and $20.6 \%$. The proportion was significantly higher in girls than in boys regardless of grade (fourth grade: $P=0.002$, seventh grade: $P<0.001$ ). The proportion of children with a family history of hypercholesterolemia (father and/or mother had a history of hypercholesterolemia) was $6.0 \%$ and $5.2 \%$ for fourth-grade boys and girls, respectively, whereas for seventh-grade boys and girls it was $5.8 \%$ and $5.7 \%$. There were no statistically significant differences between boys and girls for family history of hypercholesterolemia in either grade (fourth grade: $P=0.193$, seventh grade: $P=0.480)$. There was a statistically significant difference between boys and girls in amount of exercise in both grades $(P<0.001)$.

The associations of LDL-C with BMI, family history of hypercholesterolemia, and exercise are shown in Table 2 (fourth graders) and Table 3 (seventh graders). A higher BMI category was associated with a higher proportion of HLDL-C regardless of sex or grade level $(P<0.05)$. 
Table 1 Characteristics of subjects

\begin{tabular}{|c|c|c|c|c|c|c|c|c|c|c|}
\hline \multirow[b]{3}{*}{ Age (years) } & \multicolumn{5}{|c|}{ Fourth graders (age 9-10 years) } & \multicolumn{5}{|c|}{ Seventh graders (age 12-13 years) } \\
\hline & \multicolumn{2}{|c|}{$\begin{array}{l}\text { Boys } \\
(n=1,645)\end{array}$} & \multicolumn{2}{|c|}{$\begin{array}{l}\text { Girls } \\
(n=1,523)\end{array}$} & \multirow{2}{*}{$\begin{array}{l}P \text { - value } \\
0.751\end{array}$} & \multicolumn{2}{|c|}{$\begin{array}{l}\text { Boys } \\
(n=1,380)\end{array}$} & \multicolumn{2}{|c|}{$\begin{array}{l}\text { Girls } \\
(n=1,321)\end{array}$} & \multirow{2}{*}{$\begin{array}{l}P \text { - value } \\
0.277\end{array}$} \\
\hline & 9.0 & $(9.4)$ & 9.0 & $(9.4)$ & & 12.0 & $(12.3)$ & 12.0 & $(12.3)$ & \\
\hline Height $(\mathrm{cm})$ & 134.9 & & 134.7 & & 0.787 & 155.1 & & 153.0 & & $<0.001$ \\
\hline Weight (kg) & 30.2 & & 29.5 & & $<0.001$ & 43.8 & & 43.3 & & 0.065 \\
\hline $\mathrm{BMI}\left(\mathrm{kg} / \mathrm{m}^{2}\right)$ & 16.6 & & 16.3 & & $<0.001$ & 18.1 & & 18.3 & & 0.036 \\
\hline LDL-C (mg/dL) & 90.0 & $(92.9)$ & 95.0 & $(97.3)$ & $<0.001$ & 86.0 & $(88.9)$ & 93.0 & $(95.0)$ & $<0.001$ \\
\hline$<110(\%)$ & 81.2 & & 75.1 & & 0.002 & 84.5 & & 79.3 & & $<0.001$ \\
\hline $110-139(\%)$ & 15.2 & & 21.6 & & & 12.8 & & 17.3 & & \\
\hline $140+(\%)$ & 3.6 & & 3.3 & & & 2.8 & & 3.3 & & \\
\hline \multicolumn{11}{|c|}{ Family history of hypercholesterolemia (\%) } \\
\hline No & 94.0 & & 94.8 & & 0.193 & 94.2 & & 94.3 & & 0.480 \\
\hline Yes & 6.0 & & 5.2 & & & 5.8 & & 5.7 & & \\
\hline \multicolumn{11}{|l|}{ Exercise (\%) } \\
\hline Daily & 63.1 & & 42.0 & & $<0.001$ & 84.1 & & 59.3 & & $<0.001$ \\
\hline Sometimes & 23.4 & & 31.7 & & & 7.4 & & 13.1 & & \\
\hline None & 13.5 & & 26.2 & & & 8.6 & & 27.7 & & \\
\hline
\end{tabular}

Data are expressed as a median (mean) or percentage (\%).

*Mann-Whitney $U$-test or the chi-square test.

$B M I$, body mass index; LDL-C, low-density lipoprotein cholesterol.

Among fourth graders, the proportion of HLDL-C was higher in those with a family history of hypercholesterolemia than in those without a family history of hypercholesterolemia in both sexes (boys: $P=0.001$, girls: $P=0.037)$. Among seventh graders, there was association between HLDL-C and a family history of hypercholesterolemia in girls $(P=0.043)$, whereas there was no association between these factors in boys. The proportion of HLDL-C was higher in those who did not exercise than in those who did exercise daily, although the difference was not statistically significant for sex or grade level.

Logistic regression analysis was conducted to calculate odds ratios (ORs) for HLDL-C and their 95\% confidence

Table 2 Association of LDL-C with BMI, family history of hypercholesterolemia, and exercise among fourth graders (age 9-10 years)

\begin{tabular}{|c|c|c|c|c|c|c|c|c|c|c|}
\hline & \multicolumn{5}{|c|}{ Boys $(n=1,645)$} & \multicolumn{5}{|c|}{ Girls $(n=1,523)$} \\
\hline & \multicolumn{2}{|l|}{$<110$} & \multicolumn{2}{|c|}{$110 \leq$} & $P$ - value* & \multicolumn{2}{|l|}{$<110$} & \multicolumn{2}{|c|}{$110 \leq$} & $P$ - value \\
\hline$<50$ th & 719 & $(87.5)$ & 103 & $(12.5)$ & $<0.001$ & 606 & $(79.4)$ & 157 & (20.6) & $<0.001$ \\
\hline $50-74$ th & 345 & $(83.7)$ & 67 & $(16.3)$ & & 292 & (76.8) & 88 & $(23.2)$ & \\
\hline $75-84$ th & 129 & $(78.2)$ & 36 & $(21.8)$ & & 113 & $(74.3)$ & 39 & $(25.7)$ & \\
\hline 85 - 94th & 105 & $(64.0)$ & 59 & $(36.0)$ & & 92 & $(60.5)$ & 60 & (39.5) & \\
\hline$\geq 95$ th & 38 & $(46.3)$ & 44 & $(53.7)$ & & 41 & (53.9) & 35 & $(46.1)$ & \\
\hline \multicolumn{11}{|c|}{ Family history of hypercholesterolemia } \\
\hline No & 1269 & $(82.0)$ & 278 & $(18.0)$ & 0.001 & 1092 & $(75.6)$ & 352 & $(24.4)$ & 0.037 \\
\hline Yes & 67 & $(68.4)$ & 31 & $(31.6)$ & & 52 & $(65.8)$ & 27 & $(34.2)$ & \\
\hline \multicolumn{11}{|l|}{ Exercise } \\
\hline Daily & 831 & $(82.6)$ & 175 & $(17.4)$ & 0.126 & 468 & $(75.7)$ & 150 & $(24.3)$ & 0.595 \\
\hline Sometimes & 291 & $(78.0)$ & 82 & $(22.0)$ & & 353 & $(75.6)$ & 114 & $(24.4)$ & \\
\hline None & 171 & $(79.5)$ & 44 & $(20.5)$ & & 282 & $(73.1)$ & 104 & $(26.9)$ & \\
\hline
\end{tabular}

Data are expressed as number (\%).

*The chi-square test. 
Table 3 Association of LDL-C with BMI, family history of hypercholesterolemia, and exercise among seventh graders (age 12-13 years)

\begin{tabular}{|c|c|c|c|c|c|c|c|c|c|c|}
\hline & \multicolumn{5}{|c|}{ Boys $(n=1,380)$} & \multicolumn{5}{|c|}{ Girls $(n=1,321)$} \\
\hline & \multicolumn{2}{|l|}{$<110$} & \multicolumn{2}{|c|}{$110 \leq$} & \multirow[t]{2}{*}{$P$ - value* } & \multicolumn{2}{|l|}{$<110$} & \multicolumn{2}{|c|}{$110 \leq$} & \multirow[t]{2}{*}{$P$ - value } \\
\hline BMI percentile & & & & & & & & & & \\
\hline$<50$ th & 598 & $(86.7)$ & 92 & (13.3) & $<0.001$ & 545 & $(82.5)$ & 116 & $(17.5)$ & 0.007 \\
\hline $50-74$ th & 301 & $(87.0)$ & 45 & (13.0) & & 263 & $(79.7)$ & 67 & (20.3) & \\
\hline $75-84$ th & 120 & (87.6) & 17 & (12.4) & & 100 & $(75.8)$ & 32 & $(24.2)$ & \\
\hline $85-94$ th & 105 & (76.1) & 33 & (23.9) & & 94 & $(71.2)$ & 38 & $(28.8)$ & \\
\hline$\geq 95$ th & 42 & $(60.9)$ & 27 & $(39.1)$ & & 46 & $(69.7)$ & 20 & $(30.3)$ & \\
\hline \multicolumn{11}{|c|}{ Family history ofhypercholesterolemia } \\
\hline No & 1101 & (84.7) & 199 & (15.3) & 0.247 & 995 & $(79.9)$ & 251 & (20.1) & 0.043 \\
\hline Yes & 65 & $(81.2)$ & 15 & (18.8) & & 53 & $(70.7)$ & 22 & (29.3) & \\
\hline \multicolumn{11}{|l|}{ Exercise } \\
\hline Daily & 945 & (85.2) & 164 & (14.8) & 0.054 & 616 & $(81.7)$ & 138 & (18.3) & 0.100 \\
\hline Sometimes & 76 & (78.4) & 21 & (21.6) & & 129 & $(77.7)$ & 37 & (22.3) & \\
\hline None & 89 & (78.8) & 24 & $(21.2)$ & & 269 & $(76.4)$ & 83 & (23.6) & \\
\hline
\end{tabular}

Data are expressed as number (\%).

*The chi-square test.

intervals (95\% CIs) (Table 4). When compared to children in the $<50$ th percentile BMI category, significantly increased ORs were observed in the category of 75th to 84th percentile fourth-grade boys (OR: 1.95, 95\% CI: 1.28-2.97), 85th to 94th percentile fourth-grade boys (3.92, 2.68-5.74) and girls $(2.52,1.74-3.64)$, and 85th to 94th percentile seventh-grade boys $(2.04,1.31-3.20)$ and girls $(1.90,1.24-2.91)$. In the $\geq 95$ th percentile category, the OR significantly increased regardless of grad level or sex. Moreover, regarding the association between HLDL$\mathrm{C}$ and BMI, a significant dose-response relationship was observed regardless of grade level or sex $(P$ for trend

Table 4 Odds ratios and $95 \%$ confidence intervals for high-normal LDL-C by sex

\begin{tabular}{|c|c|c|c|c|c|c|c|c|c|c|}
\hline & \multicolumn{5}{|c|}{ Fourth graders (age 9-10 years) } & \multicolumn{5}{|c|}{ Seventh graders (age 12-13 years) } \\
\hline & \multirow[b]{2}{*}{$\mathbf{n}$} & \multicolumn{2}{|c|}{ Crude } & \multicolumn{2}{|c|}{ Adjusted* $^{*}$} & \multirow[b]{2}{*}{$\mathbf{n}$} & \multicolumn{2}{|c|}{ Crude } & \multicolumn{2}{|c|}{ Adjusted* } \\
\hline & & OR & $95 \% \mathrm{Cl}$ & OR & $95 \% \mathrm{Cl}$ & & OR & $95 \% \mathrm{Cl}$ & OR & $95 \% \mathrm{Cl}$ \\
\hline \multicolumn{11}{|l|}{ Boys } \\
\hline \multicolumn{11}{|l|}{ BMI percentile } \\
\hline$<50$ th & 822 & 1 & & 1 & & 690 & 1 & & 1 & \\
\hline $50-74$ th & 412 & 1.36 & $0.97-1.89$ & 1.35 & $0.95-1.90$ & 346 & 0.97 & $0.66-1.43$ & 0.96 & $0.65-1.44$ \\
\hline 75 - 84th & 165 & 1.95 & $1.28-2.97$ & 1.95 & $1.25-3.04$ & 137 & 0.92 & $0.53-1.60$ & 0.80 & $0.45-1.44$ \\
\hline 85 - 94th & 164 & 3.92 & $2.68-5.74$ & 3.91 & $2.61-5.84$ & 138 & 2.04 & $1.31-3.20$ & 1.94 & $1.22-3.10$ \\
\hline \multirow[t]{2}{*}{$\geq 95$ th } & 82 & 8.08 & $5.00-13.07$ & 8.16 & $4.94-13.47$ & 69 & 4.18 & $2.46-7.11$ & 4.16 & $2.39-7.24$ \\
\hline & & \multicolumn{2}{|c|}{$(P$ for trend $<0.001)$} & \multicolumn{2}{|c|}{$(P$ for trend $<0.001)$} & & \multicolumn{2}{|c|}{$(P$ for trend $<0.001)$} & \multicolumn{2}{|c|}{$(P$ for trend $<0.001)$} \\
\hline \multicolumn{11}{|l|}{ Girls } \\
\hline \multicolumn{11}{|l|}{ BMI percentile } \\
\hline$<50$ th & 763 & 1 & & 1 & & 661 & 1 & & 1 & \\
\hline $50-74$ th & 380 & 1.16 & $0.87-1.56$ & 1.17 & $0.86-1.59$ & 330 & 1.20 & $0.86-1.67$ & 1.24 & $0.87-1.76$ \\
\hline 75 - 84th & 152 & 1.33 & $0.89-2.00$ & 1.33 & $0.87-2.03$ & 132 & 1.50 & $0.96-2.35$ & 1.70 & $1.07-2.69$ \\
\hline 85 - 94th & 152 & 2.52 & $1.74-3.64$ & 2.57 & $1.75-3.78$ & 132 & 1.90 & $1.24-2.91$ & 1.95 & $1.24-3.05$ \\
\hline \multirow[t]{2}{*}{$\geq 95$ th } & 76 & 3.30 & $2.03-5.35$ & 3.28 & $1.98-5.44$ & 66 & 2.04 & $1.17-3.58$ & 2.01 & $1.12-3.63$ \\
\hline & & \multicolumn{2}{|c|}{$(P$ for trend $<0.001)$} & \multicolumn{2}{|c|}{$(P$ for trend $<0.001)$} & & \multicolumn{2}{|c|}{$(P$ for trend $<0.001)$} & \multicolumn{2}{|c|}{$(P$ for trend $<0.001)$} \\
\hline
\end{tabular}


$<0.001)$. Even when we adjusted for family history of hypercholesterolemia and exercise in the analysis, the results remained the same. The interaction of BMI and family history of hypercholesterolemia on the presence of HLDL-C was not statistically significant. Although there was an interaction between BMI and exercise for the presence of HLDL-C among seventh-grade boys $(P=0.008)$, a significantly increased OR of BMI for HLDL-C was observed in the $\geq 95$ th percentile category for each exercise group (daily, sometimes, or none).

\section{Discussion}

In the present study, the relationship between LDL-C and BMI was investigated in a large sample of population-based Japanese schoolchildren. It was found that LDL-C measured using the direct method for fourth-grade boys and girls was 90.0 and $95.0 \mathrm{mg} / \mathrm{dL}$, respectively, whereas for seventh-grade boys and girls the values were 86.0 and $93.0 \mathrm{mg} / \mathrm{dL}$. These results were similar to those in previous studies using the direct measurement of LDL-C $[15,16]$. Moreover, in our study, LDL-C level was significantly higher in girls than in boys for both grades $(P<0.001)$. These results were consistent with previous nationwide reports among Japanese children $[9,15]$. The sex difference in the results may be explained in part by the influence of hormones on LDLC among children [23,24]. Additionally, in our data, BMI was significantly higher in boys than in girls regardless of grade $(P<0.05)$. The previous study reported that sex differences in body composition are present very early in life, and are primarily attributable to the action of sex steroid hormones [25]. Accordingly, we analyzed the data separately for sex when the association between LDL-C and BMI was investigated.

A statistically significant association between LDL-C levels and a family history of hypercholesterolemia was observed among fourth graders. A previous study showed that, compared to adults, children with dyslipidemia had a stronger family or genetic background [26]. Moreover, in our study, there was a marginally significant difference between HLDL-C and exercise; physical exercise has been reported to be associated with LDL-C in children [27]. Therefore, we adjusted for these factors (a family history of hypercholesterolemia and exercise) to evaluate the relationship between LDL-C and BMI in schoolchildren.

In this study, a higher BMI category was associated with higher LDL-C levels regardless of grade or sex, which was consistent with previous studies [28-30]. Furthermore, the adjusted OR for high LDL-C among fourth graders and seventh graders reached a statistically significant level in the BMI category of greater than 85th percentile, which is classified as "overweight" if using the weight categories from the Centers for Disease Control and Prevention (CDC) [31]. Previous studies have repor- ted that children who were obese had worse lipid profiles than those who were non-obese [27-29]. Murata showed that the incidence of childhood obesity and hyperlipidemia in Japan have increased year after year, and the reason was due to increased intake of fat and an increasingly sedentary lifestyle, including decrease in physical exercise and activity [1]. Furthermore, serum lipid levels and BMI in childhood correlate strongly with those values in middle age [3]. Our data showed that a BMI in the greater than 85th percentile category (ie, overweight) was associated with a higher LDL-C. Therefore, to reduce the presence of CHD risk factors, it is important to prevent children from becoming overweight. Intervention and education programs aimed at reducing overweight among schoolchildren might help improve LDL-C levels. Early lifestyle interventions could also help manage HLDL-C, contributing to primary prevention of $\mathrm{CHD}$ in the future.

The strength of this study is that the measurement of height, weight, and LDL-C level was conducted for about 6000 population-based schoolchildren. However, potential limitations should be discussed. First of all, the present study was a cross-sectional design. Therefore, a causal relationship between LDL-C and BMI cannot be determined. In the future, longitudinal research will be necessary to address this question. Second, the subjects in this study were children from only one town in Japan, which limits generalizability to other Japanese children or other races.

\section{Conclusions}

In conclusion, the present study showed a statistically significant association between LDL-C levels and BMI in boys and girls in the fourth and seventh grades. Therefore, our study results suggest that it is important to prevent children from becoming overweight in order to help prevent the onset of hypercholesterolemia in the future.

\section{Competing interests \\ The authors declare that they have no competing interests.}

\section{Authors' contributions}

TS, HO, and TO planned this study. RN and AM contributed to improving this study in a meaningful way. TS drafted this manuscript. $\mathrm{HO}, \mathrm{RN}$, and $\mathrm{AM}$ performed the data collection. HO was in charge of the supervision of the data collection. $\mathrm{HH}$ supported the data collection. $\mathrm{HO}$ and $\mathrm{TO}$ contributed to the statistical analysis. NT and AK made substantial contributions to the

conception of this study and the revision of the manuscript. All authors read and approved the final manuscript.

\section{Acknowledgments}

The authors would like to thank all study participants, their parents and guardians, all members of the Board of Education in Ina Town, Saitama Prefecture, and the Ina-machi Conference for the Promotion and Implementation of the Childhood Lifestyle-Related Disease Prevention Examination (Chairman: Dr. Yoshihito Toriyama). This study was supported in part by Grants-in-Aid from the Ministry of Education, Culture, Sports, Science, and Technology of Japan (Nos. 14207020 and 17209024). 


\section{Author details}

'Department of Public Health, Showa University School of Medicine, 1-5-8 Hatanodai, Shinagawa-ku, Tokyo 142-8555, Japan. ${ }^{2}$ Division of Diabetes, Metabolism and Endocrinology, Department of Internal Medicine, Jikei University School of Medicine, Tokyo, Japan. ${ }^{3}$ Jikei University School of Medicine, Tokyo, Japan.

Received: 29 March 2013 Accepted: 20 May 2013

Published: 24 May 2013

\section{References}

1. Murata M: Secular trends in growth and changes in eating patterns of Japanese children. Am J Clin Nutr 2000, 72:1379S-1383S.

2. Kouda K, Nakamura H, Tokunaga $R$, Takeuchi $H$ : Trends in levels of cholesterol in Japanese children from 1993 through 2001. J Epidemiol 2004, 14:78-82.

3. Juhola J, Magnussen CG, Viikari JS, Kähönen M, Hutri-Kähönen N, Jula A Lehtimäki T, Åkerblom HK, Pietikäinen M, Laitinen T, Jokinen E, Taittonen L, Raitakari OT, Juonala M: Tracking of serum lipid levels, blood pressure, and body mass index from childhood to adulthood: the cardiovascular risk in young Finns study. J Pediatr 2011, 159:584-590

4. Tan F, Okamoto M, Suyama A, Miyamoto T: Tracking of cardiovascular risk factors and a cohort study on hyperlipidemia in rural schoolchildren in Japan. J Epidemiol 2000, 10:255-261.

5. Baker JL, Olsen LW, Sørensen Tl: Childhood body-mass index and the risk of coronary heart disease in adulthood. N Engl J Med 2007. 357:2329-2337.

6. Summary of the second report of the national cholesterol education program (NCEP) expert panel on detection, evaluation, and treatment of high blood cholesterol in adults (adult treatment panel II). JAMA 1993 269:3015-3023.

7. Imano H, Noda H, Kitamura A, Sato S, Kiyama M, Sankai T, Ohira T, Nakamura M, Yamagishi K, Ikeda A, Shimamoto T, Iso H: Low-density lipoprotein cholesterol and risk of coronary heart disease among Japanese men and women: the circulatory risk in communities study (CIRCS). Prev Med 2011, 52:381-386.

8. Takasaki Y: Serum lipid levels and factors affecting atherogenic index in Japanese children. J Physiol Anthropol Appl Human Sci 2005, 24:511-515.

9. Okada T, Murata M, Yamauchi K, Harada K: New criteria of normal serum lipid levels in Japanese children: the nationwide study. Pediatr Int 2002, 44:596-601.

10. Arai H, Yamamoto A, Matsuzawa Y, Saito Y, Yamada N, Oikawa S, Mabuch H, Teramoto T, Sasaki J, Nakaya N, Itakura H, Ishikawa Y, Ouchi Y, Horibe H, Kita T: Serum lipid survey and its recent trend in the general Japanese population in 2000. J Atheroscler Thromb 2005, 12:98-106.

11. Friedewald WT, Levy RI, Fredrickson DS: Estimation of the concentration of low-density lipoprotein cholesterol in plasma, without use of the preparative ultracentrifuge. Clin Chem 1972, 18:499-502.

12. Sundvall J, Leiviskä J, Laatikainen T, Peltonen M, Salomaa V, Vanhala M Korpi-Hyövälti E, Lauronen J, Alfthan G: The use of fasting vs. non-fasting triglyceride concentration for estimating the prevalence of high LDLcholesterol and metabolic syndrome in population surveys. BMC Med Res Methodol 2011, 11:63.

13. Okada M, Ishida R: Direct measurement of low-density-lipoprotein cholesterol is more effective than total cholesterol for the purpose of lipoprotein screening. Prev Med 2001, 32:224-229.

14. Matsushima T: Methods for direct assay of low density lipoprotein cholesterol [in Japanese]. Nihon Rinsho 2007, 65:153-158.

15. Ogawa Y, Hiura M, Kikuchi T, Nagasaki K, Iwata Y, Uchiyama M: The levels of serum low-density lipoprotein cholesterol using direct measurement in healthy Japanese school children. Clin Pediatr Endocrinol 2004, 13:55-58.

16. Yu HH, Markowitz R, De Ferranti SD, Neufeld EJ, Farrow G, Bernstein HH, Rifai N: Direct measurement of LDL-C in children: performance of two surfactant-based methods in a general pediatric population. Clin Biochem 2000, 33:89-95.

17. Nishimura R, Sano H, Matsudaira T, Miyashita Y, Morimoto A, Shirasawa T, Takahashi E, Kawaguchi T, Tajima N: Childhood obesity and its relation to serum adiponectin and leptin: a report from a population-based study. Diabetes Res Clin Pract 2007, 76:245-250.

18. Shirasawa T, Shimada N, Ochiai H, Ohtsu T, Hoshino H, Nishimura R, Morimoto A, Tajima N, Kokaze A: High blood pressure in obese and nonobese Japanese children: blood pressure measurement is necessary even in nonobese Japanese children. J Epidemiol 2010, 20:408-412.

19. Shirasawa T, Ochiai H, Nishimura R, Morimoto A, Shimada N, Ohtsu T, Hoshino H, Tajima N, Kokaze A: Secular trends in blood pressure among Japanese schoolchildren: a population-based annual survey from 1994 to 2010. J Epidemiol 2012, 22:448-453.

20. Ochiai H, Shirasawa T, Nishimura R, Morimoto A, Ohtsu T, Hoshino H, Tajima N, Kokaze A: High-molecular-weight adiponectin and anthropometric variables among elementary schoolchildren: a population-based cross-sectional study in Japan. BMC Pediatr 2012 $12 \cdot 139$

21. Ochiai H, Shirasawa T, Shimada N, Ohtsu T, Nishimura R, Morimoto A, Hoshino H, Tajima N, Kokaze A: Sleep duration and overweight among elementary schoolchildren: a population-based study in Japan. Acta Med Okayama 2012, 66:93-99.

22. Ochiai H, Shirasawa T, Nishimura R, Morimoto A, Shimada N, Ohtsu T, Hashimoto M, Hoshino H, Tajima N, Kokaze A: Eating behavior and childhood overweight among population-based elementary schoolchildren in Japan. Int J Environ Res Publ Health 2012, 9:1398-1410.

23. Laskarzewski PM, Morrison JA, Gutai J, Orchard T, Khoury PR, Glueck CJ: High and low density lipoprotein cholesterols in adolescent boys: relationships with endogenous testosterone, estradiol, and Quetelet index. Metabolism 1983, 32:262-271.

24. Kwiterovich PO Jr, Barton BA, Mcmahon RP, Obarzanek E, Hunsberger S, Simons-Morton D, Kimm SY, Friedman LA, Lasser N, Robson A, Lauer R, Stevens V, Van Horm L, Gidding S, Snetselaar L, Hantmuller WW, Greenlick M, Franklin F Jr: Effects of diet and sexual maturation on low-density lipoprotein cholesterol during puberty: the dietary intervention study in children (DISC). Circulation 1997, 96:2526-2533.

25. Wells JC: Sexual dimorphism of body composition. Best Pract Res Clin Endocrinol Metab 2007, 21:415-430.

26. Ohta T, Kiwaki K, Endo F, Umehashi H, Matsuda I: Dyslipidemia in young Japanese children: its relation to familial hypercholesterolemia and familial combined hyperlipidemia. Pediatr Int 2002, 44:602-607.

27. Escalante Y, Saavedra JM, García-Hermoso A, Domínquez AM: Improvement of the lipid profile with exercise in obese children: a systematic review. Prev Med 2012, 54:293-301.

28. Takada H, Harrell J, Deng S, Bandgiwala S, Washino K, Iwata H: Eating habits, activity, lipids and body mass index in Japanese children: the shiratori children study. Int J Obes Relat Metab Disord 1998, 22:470-476.

29. Asato Y, Katsuren K, Ohshiro T, Kikawa K, Shimabukuro T, Ohta T: Relationship between lipid abnormalities and insulin resistance in Japanese school children. Arterioscler Thromb Vasc Biol 2006, 26:2781-2786.

30. Takahashi $H$, Hashimoto N, Kawasaki T, Kikuchi T, Uchiyama M: The usefulness of measurement body fat deposition for detecting obesity and atherogenesity in Japanese school children. Acta Paediatr Jpn 1996, 38:634-639

31. Kuczmarski RJ, Ogden CL, Grummer-Strawn LM, Flegal KM, Guo SS, Wei R, Mei Z, Curtin LR, Roche AF, Johnson CL: CDC growth charts: United States. Adv Data 2000, 314:1-27.

\section{doi:10.1186/1476-511X-12-77}

Cite this article as: Shirasawa et al:: LDL-cholesterol and body mass index among Japanese schoolchildren: a population-based crosssectional study. Lipids in Health and Disease 2013 12:77.

\section{Submit your next manuscript to BioMed Central and take full advantage of:}

- Convenient online submission

- Thorough peer review

- No space constraints or color figure charges

- Immediate publication on acceptance

- Inclusion in PubMed, CAS, Scopus and Google Scholar

- Research which is freely available for redistribution 